\title{
COMPORTAMENTO INFORMACIONAL DOS GESTORES DE ASSUNTOS ESTUDANTIS DAS UNIVERSIDADES FEDERAIS DO BRASIL
}

\author{
INFORMATIONAL BEHAVIOR OF STUDENT AFFAIRS \\ MANAGERS FROM FEDERAL UNIVERSITIES IN BRAZIL
}

\author{
Rosilane de Oliveira Castro de Souzaa \\ Helena de Fátima Nunes Silvab
}

\begin{abstract}
RESUMO
Introdução: O Comportamento Informacional se refere as muitas maneiras pelas quais as pessoas interagem com a informação, em particular, as formas pelas quais 0 indivíduo percebe, busca, entende e usa a informação nos vários contextos da vida. Objetivo: $O$ artigo apresenta resultado de pesquisa de mestrado que analisou 0 comportamento informacional dos gestores de assuntos estudantis das universidades federais do Brasil. Metodologia: Trata-se de uma pesquisa de caráter descritivo com abordagem qualiquantitativa. A coleta de dados decorreu com aplicação de questionário, entrevista semiestruturada e análise documental dos documentos gerados pelo Fórum Nacional de Pró-Reitores de Assuntos Estudantis. A pesquisa norteou-se pelo modelo de Comportamento Informacional desenvolvido por Wilson (1981/1996). Resultados: Foram apontadas necessidades de informações para sanar dúvidas, tomar decisões e gerar conhecimento. Quanto à busca por informações, foi apontado o contato pessoal como a principal fonte de informação, notou-se a presença de algumas barreiras de tempo e tecnologia (falta de um sistema padronizado e integrado). As informações são utilizadas para elaboração de políticas e ações para a assistência estudantil, prestação de contas e, principalmente, para tomada de decisões. O compartilhamento da informação ocorre pelo grupo de e-mail Ciranda e pelo WhatsApp, sendo levados em consideração a proximidade organizacional, a confiança e os riscos percebidos Conclusões: É possível melhorar o acesso dos gestores à informação que necessitam, disponibilizando o recurso e fontes relevantes e confiáveis, conscientizando-os da utilização de ferramentas mais perenes que permitam o acesso, o armazenamento, a recuperação e uso da informação, possibilitando-lhes tomar decisões mais assertivas.
\end{abstract}

Descritores: Informação. Comportamento Informacional. Assistência Estudantil. Fonaprace.

\footnotetext{
a Mestre em Gestão da Informação pela Universidade Federal do Paraná (UFPR). Técnico Adminstrativo da Universidade Federal do Paraná (UFPR). E-mail: rosilanecastro82@gmail.com.

b Doutora em Engenharia de Produção pela Universidade Federal de Santa Catarina (UFSC). Docente do Programa de Pós-Graduação em Gestão da Informação, da Universidade Federal do Paraná (UFPR). E-mail: helenanuness@gmail.com.
} 


\section{INTRODUÇÃO}

A informação é um recurso organizacional que precisa ser gerenciado. É o uso da informação e não somente a sua existência que permite a tomada de decisões melhores. Identificar as formas de obtenção, seu processamento e uso das informações são fundamentais para o alcance dos objetivos estratégicos e o sucesso de qualquer organização.

Assim como nas organizações privadas, os gestores das Instituições Federais de Ensino Superior (IFES) necessitam administrar diariamente as informações que Ihes cabem, a fim de prestarem um serviço com melhor qualidade e eficiência.

Com as políticas de cotas do Governo Federal, houve um aumento no ingresso de estudantes com fragilidade socioeconômica nas Universidades Públicas Federais, entretanto, muitos deles acabam desistindo do curso por não terem condições de se manterem na Universidade. Diante deste contexto, a assistência estudantil tem sido essencial. O papel desempenhado pelos gestores de assuntos estudantis por meio do Fórum Nacional de Pró-Reitores de Assuntos Estudantis (FONAPRACE) é fundamental para a luta e garantia aos direitos da assistência estudantil e a permanência desses estudantes nas Universidades.

Diante do cenário brasileiro de contenção de gastos, de reestruturação de políticas de recursos financeiros e apoio à educação, é importante entender como os gestores de assuntos estudantis das universidades federais brasileiras se comportam em relação às informações, pois eles contribuem para a formulação de políticas e ações para a assistência estudantil, além de administrarem o dinheiro público.

Dessa forma, o artigo apresenta os resultados de pesquisa de mestrado realizada com o objetivo de analisar o comportamento informacional dos gestores de assuntos estudantis das universidades federais. Para tanto, utilizouse de uma pesquisa qualiquantitativa, com análise documental, aplicação de questionário e entrevista semiestruturada.

\section{REFERENCIAL TEÓRICO}




\subsection{COMPORTAMENTO INFORMACIONAL}

Os estudos do comportamento informacional, também denominados de estudo do usuário (ARAÚJO, 2010; RODRIGUES; CARDOSO, 2017) remontam à década de 1940. Gasque e Costa (2010) apontam que houve uma evolução global no enfoque dos estudos, partindo de uma perspectiva mais restrita para uma mais abrangente tanto no que se refere aos conceitos e metodologias como também ao grupo de usuários estudados. Os objetos dos estudos passaram de uma orientação centrada em sistemas para uma orientação voltada ao usuário, deixando de focar em determinadas tarefas ou atividades de informação para atender a situação pessoal, social ou organizacional na qual a informação surge e onde será colocada em prática (PEREIRA, 2010).

Ao longo dos anos, os estudos sobre os usuários foram desenvolvidos sob diferentes abordagens, partindo da Abordagem Tradicional, para uma Abordagem Alternativa/Cognitiva e posteriormente para a Abordagem Social.

A Abordagem Tradicional considera a informação como algo externo, objetivo, que existe fora do indivíduo e pode ser definida, medida e utilizada por diferentes usuários da mesma forma, bastando apenas ser descoberta nos sistemas de informações (CHOO, 2006; PEREIRA, 2010). Nesta abordagem, o usuário é considerado apenas como um dos integrantes do sistema, um informante que de forma passiva, precisa se adaptar aos sistemas de informação.

$\mathrm{Na}$ Abordagem Alternativa, o usuário passa a ser o centro das atenções, portanto, os estudos levam em consideração os aspectos cognitivos e psicológicos do indivíduo, buscando conhecer as necessidades de cada um. (ARAÚJO, 2009; RODRIGUES; CARDOSO, 2017). O indivíduo não é visto somente como aquele que recebe a informação, mas como o produtor dela por suas interações, percepções e processos mentais, ao passo que uma mesma informação pode ter significados distintos individualmente de pessoa para pessoa.

Na Abordagem Social (GUASQUE; COSTA, 2010; ARAÚJO, 2016), as investigações do comportamento informacional passaram a considerar além dos fatores cognitivos, os fatores sociais, culturais, afetivos e situacionais que, interagindo entre si e com o usuário, formavam o contexto que poderia influenciar 
no comportamento deste usuário.

As pesquisas produzidas pela abordagem social investigam 0 comportamento dos usuários nas diversas situações que compõe a vida cotidiana e apresentam uma visão holística da vida do usuário e o modo como se comporta em relação à informação nos diversos momentos, seja no trabalho, nas tarefas domésticas ou nos momentos de lazer.

Araújo (2016) destaca que as três abordagens apontadas para estudar o usuário da informação não são excludentes, mas, sim complementares, na medida que cada uma foi construída para identificar e estudar determinados aspectos da realidade.

O comportamento informacional pode ser compreendido como a totalidade do comportamento humano em interação com o uso de fontes e canais de informação (WILSON, 2000), se refere as formas pelas quais o indivíduo percebe, busca, entende e usa a informação nos vários contextos da vida (BATES, 2010; TARAPANOFF, 2011; DU, 2014; CASE, 2016).

O Comportamento Informacional inclui dentro do seu campo de estudo três elementos básicos: a necessidade de informação, o processo de busca da informação e o uso da informação (WILSON, 1999).

Necessidade de informação é o desejo de um indivíduo ou de um grupo de localizar e obter informações para satisfazer uma necessidade consciente ou inconsciente, decorre de uma percepção que algo está faltando e culmina na localização de informação que contribui para a compreensão e significado (DAS; ACHARY, 2014; UCHE; NDIDI, 2018). O indivíduo identifica que precisa de mais informação para dar continuidade a uma determinada tarefa, em nível pessoal ou profissional, atingir uma meta ou para resolver um problema (WILSON, 1999; SECO; SANTOS; BARTALO, 2016; CASE, 2016).

O comportamento de busca informacional se refere à busca intencional para obter informações como consequência de uma necessidade de satisfazer algum objetivo (WILSON, 1999), na qual o indivíduo interage com os espaços ou ferramentas que possibilitam 0 acesso à informação (NASCIMENTO; VITORIANO, 2017).

O comportamento de uso da informação refere-se à incorporação de 
informações na base de conhecimento existente em cada indivíduo (VITORIANO; GASQUE, 2018). O uso da informação acontece quando a pessoa age, utilizando a informação encontrada, com o objetivo de resolver um problema, tomar uma decisão ou aumentar sua compreensão e seu conhecimento (MACHADO; BARBOSA, 2018). Selecionar ou não a informação depende da sua relevância para o esclarecimento ou solução do problema.

Os modelos de comportamento informacional foram objetos de estudo dos autores Derwin (2003), Wilson (1981/1996), Ellis (1989), Kuhlthau (1993) e Choo (2003). A Figura 1 apresenta uma síntese de cada um deles.

Figura 1 - Modelos de Comportamento Informacional

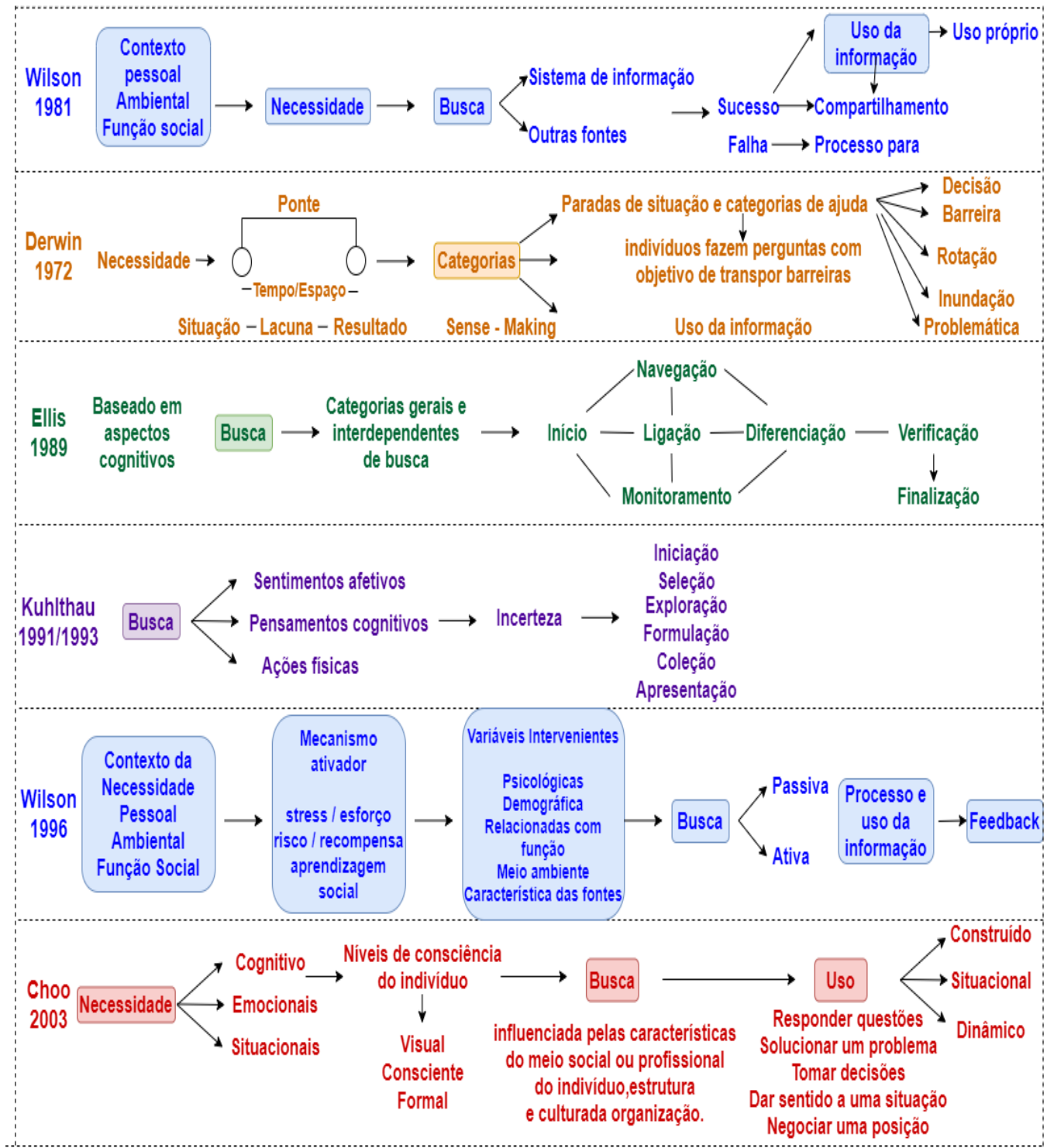

Fonte: Elaborado pela autora com base em Kuhlthau (1993), Wilson (1999), Derwin (2003) e Choo (2003). 
Nesta pesquisa optou-se pelo Modelo de Wilson (1981/1996), buscando abordar as necessidades informacionais, as variáveis intervenientes, os fatores motivadores, o processo de busca e uso das informações.

\subsection{MOdELO DE COMPORTAMENTO INFORMACIONAL WILSON (1981/1996)}

Wilson apresenta dois Modelos de Comportamento Informacional. No primeiro modelo, o autor parte do entendimento de que a busca da informação surge a partir de uma necessidade humana e, é o desejo de satisfazer esta necessidade que desperta os indivíduos para a procura de informações (WILSON, 1999). O modelo ilustra a ideia de que cada usuário possui necessidade de informação, as quais são externalizadas como demandas que podem ou não ser atendidas por um sistema ou outras fontes de informação.

O modelo destaca que quando há demanda para a busca de informações, elas não ocorrem apenas nos sistemas ditos tradicionais, como bibliotecas ou centros de informação, mas também pode dar-se em outras fontes que não tem a finalidade principal de fornecer serviços de informação. Quanto ao uso da informação, está condicionado ao sucesso obtido na busca, ou seja, se a tentativa de encontrar a informação tiver sucesso, o usuário poderá fazer uso desta informação, caso contrário, interrompe-se esta busca e o usuário começará um novo processo de busca da informação (WILSON, 1999).

Outros componentes importantes apresentados neste modelo dizem respeito à troca de informações e aos fracassos informacionais que podem ocorrer no contato com outras pessoas (TARAPANOF, 2011). O uso da informação pode servir para satisfação da necessidade do próprio indivíduo ou para transferência para terceiros.

Demonstrado separadamente, o Modelo de Comportamento de Busca de Informação apresenta um grupo de categorias fundamentais de fatores e causas que produzem uma necessidade de informação, introduzindo a ideia de contexto pessoal, ambiental e função social, os quais originam uma necessidade de informação e, consequentemente, o comportamento de busca da informação.

Este modelo foi inspirado nas necessidades fisiológicas, cognitivas e 
afetivas dos indivíduos e baseou-se em duas proposições principais: primeiro, que a necessidade de informação não é uma necessidade primária, mas uma necessidade secundária; e segundo, que no esforço para descobrir informações para satisfazer uma necessidade, o usuário pode se deparar com barreiras de natureza pessoal, interpessoal e ambiental. $O$ contexto dessas necessidades seria figurado pelo próprio indivíduo, pelas demandas de seu papel na sociedade e pelo meio ambiente em que sua vida e seu trabalho desenrolam (MARTíNEZSILVEIRA; ODDONE, 2007).

Em 1996, Wilson e Walsh propõem um novo modelo de comportamento informacional, utilizando a mesma estrutura do modelo proposto em 1981 no qual a pessoa em contexto permanece no foco da necessidade de informação, as barreiras são representadas pelas variáveis intermitentes e o comportamento de busca é identificado.

Para este novo modelo, foram usados dados de pesquisas de outros campos, incluindo administração, psicologia, comunicação em saúde e pesquisa do consumidor e extraiu vários pontos significativos do comportamento informacional para identificar os fatores que compõe o seu modelo. Segundo Wilson (1999), são esses fatores que influenciam a ocorrência da necessidade de informação (assim como a sua percepção e o modo pelo qual tal necessidade será satisfeita), tais fatores podem ser de natureza pessoal, social/interpessoal ou ambiental.

Os fatores de natureza pessoal abrangem as variáveis psicológicas as quais incluem a perspectiva na vida e no sistema de valores, orientação política, conhecimento, variáveis emocionais, atitudes para inovação, estereótipos, preferências, preconceitos, autopercepção, interesses e conhecimento do assunto e, as variáveis demográficas que incluem sexo, idade, estado social e econômico, educação e experiencia de trabalho.

Os fatores sociais abrangem as variáveis interpessoais (de caráter profissional) incluem as exigências, os regulamentos e as limitações; os padrões de comportamento estabelecidos (em uma categoria profissional em particular); o lugar que uma pessoa ocupa em uma organização ou em um sistema de organizações; a hierarquia típica de valores; e o nível de responsabilidade. 
Por fim, os fatores ambientais incluem as variáveis ambientais que podem ser analisadas no âmbito de um país, organização ou no setor, ou seja, a legislação, situação econômica, nível de estabilização, cultura informacional, tecnologia da informação dentre outros $e$, as características das fontes informacionais, como localização e tipo de acessos, interface, linguagens. O uso da expressão "variáveis intervenientes" sugere que seu impacto pode ser tanto no suporte do uso quanto previamente ao uso (WILSON, 1999).

Um novo conceito abordado neste Modelo de Wilson (1996) diz respeito aos mecanismos de ativação, segundo o autor, nem toda a necessidade oferece um incentivo para empreender atividades que conduzam a buscar informações, portanto, é importante descobrir o que estimula e motiva a busca pela informação.

Wilson (1999) reconhece que existem vários tipos de comportamento de busca de informação, entre eles, busca passiva, busca contínua e busca ativa, sendo esta última o foco de atenção. Quanto ao processamento e uso da informação, o autor aponta que é uma parte necessária do feedback do processo para constatação se as necessidades de informação foram atendidas, caso não tenham sido atendidas, o processo de busca pode ser iniciado novamente.

O segundo modelo de Wilson é mais complexo do que o seu primeiro modelo de 1981, pois além de identificar as possíveis variáveis pessoais e os modos de busca de informação, também sugere teorias relevantes de motivações por trás do comportamento de busca (CASE, 2016).

\section{PROCEDIMENTOS METODOLÓGICOS}

A pesquisa se caracteriza como exploratória descritiva. Segundo Gil (2008, p. 28), a pesquisa descritiva tem por objetivo descrever as características de determinada população ou fenômeno e envolve o uso de técnicas padronizadas de coleta de dados, assumindo em geral, a forma de levantamento. Foram adotados a abordagem qualiquantitativa e o método não probabilístico, trabalhando com todo o universo em potencial composto por 65 gestores que integram o Fórum Nacional de Pró-Reitores de Assuntos Estudantil 
(FONAPRACE). A escolha do Fórum como ambiente de pesquisa se deu pelo fato de aglutinar todos os gestores de assistência estudantil das universidades federais, facilitando o acesso a eles.

A coleta de dados ocorreu por meio de pesquisa documental, questionário e entrevista semiestruturada. A análise documental foi realizada nos documentos gerados pelo FONAPRACE e nos e-mails trocados pelos Gestores de Assuntos Estudantis no Grupo Ciranda. A aplicação do questionário e as entrevistas foram realizadas no II Encontro Nacional de Pró-Reitores de Assuntos Estudantis que ocorreu em Brasília nos dias 30 e 31 de outubro de 2019.

Para o questionário foi utilizado escala de medição, cuja proposição foi medida em termos de Frequência e Importância. O questionário com escalas de medidas, atende à pesquisa social, também entendida como qualiquantitativa, pois une os interesses quantitativos de informações e os aspectos qualitativos interpretativos, permitindo ao pesquisador "ler" e interpretar os dados que coletaram e saber o que os respondentes estão realmente dizendo, ainda que de forma indireta (MICHEL, 2015). Houve um retorno de 26 questionários e quatro pró-reitores foram selecionados para a entrevista, considerando-se o tempo de exercício no cargo.

A análise documental foi realizada com a técnica de análise de conteúdo, composta pelas etapas de (i) pré-análise; (ii) exploração do material; (iii) 0 tratamento dos resultados, inferência e a interpretação (BARDIN, 2016). O sistema de categorias foi elaborado previamente, com base na literatura sobre a temática Comportamento Informacional, sendo definidas quatro Categorias de Contexto: (i) necessidade (ii) busca, (iii) uso e (iv) compartilhamento da informação.

\section{APRESENTAÇÃO E DISCUSSÃO DOS RESULTADOS}

A apresentação e discussão dos resultados obtidos relaciona-se aos objetivos específicos da pesquisa, quais sejam, identificar o contexto e as necessidades de informações, mapear as práticas de buscas e as fontes utilizadas, identificar as práticas de uso e o compartilhamento de informações 
pelos gestores de assuntos estudantis das universidades federais brasileiras.

Os gestores de assuntos estudantis se reúnem no FONAPRACE que é representado por 63 Universidades Federais e dois (2) Centros Tecnológicos. Participaram da pesquisa 18 Pró-Reitores, 1 Sub-Reitor, 2 Diretores, 1 Coordenador, 2 Assessores e 2 Superintendentes, sendo que $73 \%$ eram do sexo masculino e $27 \%$ feminino. Dos 26 respondentes do questionário, 7 pertencem a região Sudeste, 6 pertencem a região Centro Oeste, 5 são da região Sul, 4 da região Norte e 4 da região Nordeste.

\subsection{NECESSIDADES DE INFORMAÇão}

Os Gestores de Assuntos Estudantis, além de assumirem os compromissos com o FONAPRACE precisam lidar, diariamente, com suas atividades nas Instituições de Ensino onde exercem o seu cargo, dessa forma, enfrentam situações que geram necessidades de diversos tipos de informações.

As necessidades informacionais são influenciadas pelo contexto onde os Gestores estão envolvidos, pois, como apontado por Wilson (1999), elas não existem por si só, mas, são determinadas pelo ambiente no qual os indivíduos desempenham suas atividades, o seu papel social no trabalho e suas necessidades pessoais, sejam elas de natureza psicológica, afetiva ou cognitiva.

O ambiente organizacional dos Gestores de Assuntos Estudantis é constituído pelos fatores e fluxo de informação relacionados à definição de ações para criação de políticas e diretrizes para a Assistência Estudantil. Destacam-se entre elas: a elaboração de ações e metas a serem cumpridas pelo FONAPRACE, a gestão do recurso do Programa Nacional de Assistência Estudantil (PNAES), a identificação de indicadores que possam aferir os avanços obtidos com o acolhimento dos estudantes com vulnerabilidade econômica e os próprios resultados numéricos alcançados, como o número de estudantes beneficiados pelos programas de assistência estudantil e o impacto dos auxílios para a formação desses estudantes.

A conjuntura socioeconômica e política do país foi apontada no contexto informacional. Com a mudança de governo em 2018, percebe-se uma 
preocupação dos gestores das universidades públicas federais na manutenção dos recursos disponibilizados para a assistência estudantil, isto somado aos cortes anunciados para a educação, o número de pessoas desempregadas refletindo diretamente na maior procura por assistência estudantil, traz incertezas quanto ao futuro da permanência dos estudantes com fragilidade socioeconômica nas universidades.

Choo (2006) aponta que as necessidades de informação são muitas vezes entendidas como as necessidades cognitivas de uma pessoa, falhas ou deficiências de conhecimento ou compreensão. Questionados quanto ao reconhecimento das suas necessidades informacionais, os gestores afirmaram reconhecer a necessidade de determinada informação para (i) sanar dúvidas, principalmente, quanto aos auxílios oferecidos, forma de distribuição destes auxílios, funcionamento dos Restaurantes Universitários, perfil e rendimento acadêmico dos estudantes que pleiteiam bolsas, além de dúvidas cotidianas pertinentes ao cargo; (ii) tomar decisões e (iii) gerar conhecimento.

\subsection{BUSCA DE INFORMAÇÃO}

No processo de busca de informação, foram analisados os tipos de informações, as principais fontes utilizadas, as barreiras encontradas e os sentimentos percebidos neste processo.

As informações utilizadas pelos Gestores de Assistência Estudantil, são em geral, aquelas que possibilitam definir soluções para uma boa gestão do recurso do PNAES, visando atender o maior número possível dos estudantes com vulnerabilidade socioeconômica nas suas instituições, criando programas que permitam a permanência destes estudantes na universidade até a conclusão do seu curso. Destarte, essas informações permitem a elaboração de ações para a criação de políticas e diretrizes para a Assistência Estudantil.

Entretanto, tem toda a parte de Gestão da Pró-Reitoria, que envolve a contratação e coordenação da equipe técnica, administração dos recursos financeiros para custeio da sua unidade, contratação de serviços, aquisição de bens e materiais, dentre outras. A Tabela 1 apresenta os principais tipos de 
informações buscadas nas instituições de ensino onde os gestores atuam.

Tabela 1 - Tipos de informações buscadas nas IFES

\begin{tabular}{l|c}
\hline \multicolumn{1}{c|}{ Tipo de informações } & $\%$ \\
\hline Orçamento e Finanças & $81 \%$ \\
\hline Quantidade de refeições no restaurante universitário & $77 \%$ \\
\hline Perfil socioeconômico do estudante & $65 \%$ \\
\hline Acompanhamento social/pedagógico do estudante & $58 \%$ \\
\hline Taxa de evasão & $50 \%$ \\
\hline Quantidade de estudantes PCD & $50 \%$ \\
\hline Estado de saúde (doença mental) do estudante & $42 \%$ \\
\hline Processos licitatórios & $35 \%$ \\
\hline Capacitação dos servidores & $31 \%$ \\
\hline Contratação de pessoal & $31 \%$ \\
\hline
\end{tabular}

Fonte: Dados da pesquisa (2020)

Orçamento e Finanças é o tipo de informação mais buscada e utilizada pelos gestores, visto que, precisam estar atentos aos recursos disponíveis e sua utilização durante o exercício financeiro. A quantidade de refeições utilizadas nos restaurantes universitários também foi apontada por $77 \%$ dos gestores, pois, parte delas, são subsidiadas pelas universidades aos estudantes com vulnerabilidade econômica, portanto, os gestores tomam decisões para um melhor gerenciamento do restaurante, considerando a possibilidade de terceirizar o serviço ou não.

O canal mais valorizado na busca de informações para atender as necessidades dos Gestores de Assuntos Estudantis são os contatos pessoais internos ou externos. Quase $80 \%$ dos respondentes do questionário informaram que utilizam este tipo de canal nas suas buscas, com muita frequência.

A Internet foi apontada por $60 \%$ dos respondentes como o canal externo mais utilizado na obtenção de informações diárias, mais precisamente, sites de pesquisas como o Google, seguidos dos sites institucionais. Tal fato corrobora com os estudos de Malaquias et al. (2017) e Kwasitsu e Chiu (2019) ao apontarem a Internet como um dos principais canais de informações.

Quanto às Fontes de informações, constatou-se a partir da análise de frequência de uso, conforme a classificação de fontes apontadas por Rodrigues e Blattmann (2014) e Pereira (2016), que há uma preferência pelas fontes 
pessoais internas e pelas fontes impessoais internas e externas. Os colegas de trabalho são frequentemente consultados nas suas buscas por informações, sendo apontados como a fonte mais relevante.

A cada Encontro do FONAPRACE, são gerados documentos que norteiam ações a serem tomadas perante a Assistência Estudantil junto às Universidades e Governo Federal, dessa forma, constatou-se que esses documentos também são consultados pelos Gestores como fontes de informação, assim como, os ofícios e memorandos emitidos pelo MEC e pelas Instituições de Ensino onde desempenham suas atividades.

As principais fontes de informações identificadas com a análise documental e as entrevistas e, que são utilizadas pelos gestores são: (i) contato pessoal, (ii), Encontro presencial no FONAPRACE, (iii) Grupo de WhatsApp, (iv) Grupo de e-mail Ciranda, (v) Observatório Nacional de Acompanhamento de Políticas de Assistência Estudantil e (vi) Pesquisas Socioeconômicas dos estudantes de Graduação das IFES.

Em 1999, a Coordenação do FONAPRACE criou um Grupo de E-mail para possibilitar a troca de informações entre os seus membros, sendo este considerado uma fonte formal de comunicação, o qual recebeu o nome de Ciranda. Entretanto, com as novas tecnologias disponíveis e pela maior facilidade e rapidez de comunicação, foi criado um Grupo de WhatsApp, que conforme observado pela análise de conteúdo, é a fonte mais utilizada pelos Gestores de Assuntos Estudantis.

O Entrevistado $D$ destaca a importância desta fonte em sua fala:

A gente, no nosso grupo de WhatsApp do FONAPRACE, enfim..., tem todas aquelas chatices de grupos de WhatsApp: bom dia, boa tarde, boa noite, coração e tal, mas, tudo bem, todo mundo já se acostumou com isso. Mas ali, é um espaço fundamental de busca de informações. As vezes informações bem técnicas, ah, vocês estão retirando estudantes indígenas da bolsa MEC, aqueles que não atingiram um rendimento estabelecido, sim ou não? E as universidades vão dizendo, sim, não, sim, não, eu não retiro, então como é que a gente vai fazer? E muitas vezes, essas conversas, elas geram pauta no FONAPRACE e a gente tira algumas decisões dali. O que nós vamos fazer? A gente usa muito essas informações. São dúvidas que vão surgindo, ou interpretações de documentos que a gente vai postando ali no whats app. Por incrível que pareça, 
a gente usa muito mais o WhatsApp do que o e-mail. O e-mail é muito mais formal..., pra você ter os documentos guardados, mas essa informação rápida, ela é do grupo de WhatsApp.

Entretanto, percebe-se uma preocupação quanto ao uso exclusivo desta fonte, uma vez que a dinâmica de comunicação é muito intensa e muitas informações podem ser perdidas.

Dessa forma, visando centralizar todas as informações, constatou-se a existência do Observatório Nacional de Acompanhamento de Políticas de Assistência Estudantil que prevê a construção de um site com três objetivos: (i) a constituição de um espaço virtual de comunicação e troca de informações entre as IFES sobre os instrumentos e estratégias nas ações da assistência estudantil brasileira em nível nacional, (ii) a constituição de um repositório de documentos legais, documentos produzidos pelas IFES, relatórios e resultados de pesquisas, textos acadêmicos e (iii) a constituição de um Banco de Dados contendo informações sobre o perfil socioeconômico dos estudantes das IFES e sobre a estrutura e ações das IFES no campo da assistência estudantil.

Cabe ressaltar a importância do Observatório, pois permitirá a criação de memória organizacional do FONAPRACE e fornecerá a recuperação da informação, o que até então, não é assegurado com o uso do WhatsApp. Para àqueles gestores que assumirem o cargo, isso certamente fará muita diferença, pois terão à sua disposição uma plataforma com informações armazenadas, permitindo o acesso, compartilhamento e o uso delas.

Por fim, outra Fonte de Informação que tem sido muito consultada pelos Gestores de Assuntos Estudantis são as Pesquisas Socioeconômicas e Cultural dos Graduandos das IFES brasileiras, realizadas por equipe especializada, sob a responsabilidade do FONAPRACE e da ANDIFES. Ao todo, já foram realizadas cinco pesquisas (1996, 2003, 2010, 2014 e 2018) que demonstraram o perfil dos estudantes de graduação das Universidades Públicas Brasileiras.

Os dados das Pesquisas Socioeconômica dos estudantes serviram para subsidiar a criação do Programa Nacional de Assistência Estudantil, oferecendo argumentos convincentes para legitimar a luta travada pelo FONAPRACE/ANDIFES em favor da criação de uma política nacional de Assistência Estudantil junto à sociedade brasileira e às esferas governamentais. 
Dessa forma, os resultados das pesquisas contribuíram para desmistificar a percepção, inculcada no imaginário do senso comum, de que os estudantes das IFES, seriam na sua maioria, oriundos de famílias dos estratos econômicos mais ricos (FONAPRACE, 2018).

Durante o processo de busca da informação, foram apontadas algumas barreiras identificadas pelos Gestores de Assuntos Estudantis, as quais Wilson (1999) denominou de variáveis intervenientes, que são influenciadas por fatores de natureza pessoal, social, ambiental e, surgem do contexto informacional onde os Pró-Reitores estão inseridos (MARTINÉZ-SILVEIRA; ODONNE, 2007).

A principal delas é a falta de um sistema padronizado e integrado para a Gestão das Bolsas oferecidas com o Programa de Assistência Estudantil. Embora sigam os critérios exigidos pelo Decreto 7.234 de 2010, cada uma das IFES possui autonomia para estabelecer os seus programas, inclusive os valores das bolsas variam de uma universidade para outra.

Dessa forma, ao procurar dados sobre os estudantes e sobre a assistência estudantil, a fim de extrair informações que possam lhes ajudar na gestão, verifica-se que eles são apresentados das formas mais diversificadas possíveis, não existindo um padrão entre as IFES para este fim, inclusive para responder os relatórios de prestação de contas para o MEC. Isso caracteriza, conforme descrito por Wilson (1999), uma variável interveniente que é influenciada por fatores ambientais (tecnologia da informação).

A barreira Tempo, foi a segunda mais frequentemente indicada. Foi levantado que por conta das rotinas diárias intensas, muitas informações deixam de ser buscadas pela falta de tempo. Por exemplo, os resultados encontrados com as produções científicas que poderiam trazer maiores subsídios para tomada de decisões e criação de novas políticas de Assistência Estudantil.

Kuhlthau (1993) afirma que a busca de informação é um processo de construção o qual envolve toda a experiência da pessoa, sentimentos, pensamentos e ações, portanto, ao analisar o processo de busca, não se deve considerar apenas as ações físicas, mas, deve-se investigar os seus pensamentos cognitivos e sentimentos afetivos.

Dessa forma, foi apontado que $62 \%$ dos gestores identificam o sentimento 
de Curiosidade frequentemente durante suas buscas por informações. Sentimentos de incertezas ( $46,15 \%)$, também tiveram destaques, seguidos pelos sentimentos de estresse e aflição (ambos com 42,31\%).

Embora não tenha ocupado as primeiras posições para os respondestes do questionário, observou-se com a análise documental e pelas falas nas entrevistas que os sentimentos de ansiedade e medo são percebidos na busca por informações, principalmente, por conta da atual situação do país, com as ameaças de contingenciamento e cortes do recurso destinado ao PNAES pelo Governo Federal.

O entrevistado A comenta "temos um campo extremamente nebuloso que acaba gerando incertezas e ansiedades", seja para buscar informações ou tomar decisões. Este comentário corrobora com o "princípio da incerteza" destacada por Kuhlthau (1993), que é um estado cognitivo que normalmente causa sentimento de ansiedade, ou seja, essas incertezas favorecem o início do processo de busca por informações por parte dos Gestores de Assuntos Estudantis. À medida que as coisas vão se tornando mais claras, esses sentimentos tendem a ser substituídos por sentimentos de confiança, associado aos sentimentos de alívio, satisfação e de um senso de direção.

O fato de conhecerem fontes confiáveis, garante, portanto, qualidade na informação a ser recuperada e contribui para o repasse das informações (BAGGIO; COSTA; BLATTMANN, 2016).

Por fim, os fatores motivadores da busca por informação são identificados pela convicção de que quanto mais informações tiverem, maior assertividade terá nas tomadas de decisões e na resolução de problemas. A instabilidade causada pela redução dos recursos também foi destacada como um fator motivacional de busca por informação, visto que, os Gestores precisam estar atentos a todos os acontecimentos, uma vez que isso atingirá diretamente na sua gestão.

\subsection{USO DA INFORMAÇÃo}

Choo (2006) aponta que o uso da informação envolve a seleção e o 
processamento da informação, visando responder uma pergunta, resolver um problema, tomar uma decisão, negociar uma posição ou entender uma situação.

Dessa forma, foram elencados os principais propósitos de uso para as informações, conforme demonstrado na Tabela 2.

Tabela 2 - Frequência do uso das informações

\begin{tabular}{|c|c|}
\hline Uso das informações & 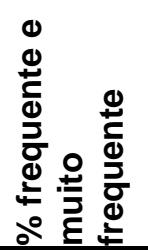 \\
\hline Elaboração de metas/ações para $\mathrm{AE}$ & $92,31 \%$ \\
\hline Políticas Afirmativas e Acessibilidade & $76,92 \%$ \\
\hline Relatórios para prestação de contas & $84,62 \%$ \\
\hline Tomada de decisão & $96,15 \%$ \\
\hline Aquisição de bens e materiais & $38,46 \%$ \\
\hline Composição equipe de trabalho & $57,69 \%$ \\
\hline Propor debates sobre doenças mentais & $50,00 \%$ \\
\hline Propor cursos e oficinas & $57,69 \%$ \\
\hline Fazer parcerias com outras instituições & $38,46 \%$ \\
\hline
\end{tabular}

Fonte: Dados da pesquisa (2020)

Constatou-se que praticamente todos os respondentes do questionário $(96,15 \%)$ apontaram que usam frequentemente e muito frequentemente as informações para Tomada de Decisão, Elaboração de metas/ações para a Assistência Estudantil e Formulação de Relatórios para prestação de contas foram apontados em segundo e terceiro lugar, respectivamente. Além desses propósitos de uso, verificou-se através da análise documental que os Gestores também usam as informações para criação de conhecimento.

Identificou-se que os Gestores usam as informações para satisfazer as suas próprias necessidades, assim como, transferem essa informação para outras pessoas, seja na instituição de ensino onde trabalham ou no próprio FONAPRACE (TARAPANOFF, 2011). Percebe-se o fluxo de mão dupla descrito por Wilson (1999). Constatou-se uma preferência da utilização da informação em meio digital devido a facilidade, rapidez, agilidade, economicidade e sustentabilidade (ARAÚJO; FACHIN, 2015). 


\subsection{COMPARTILHAMENTO DA INFORMAÇÃo}

Evidenciou-se que há disposição de compartilhar informações (DAVENPORT; PRUSAK, 1998), pois os Gestores possuem o sentimento de coletividade (SILVA; BINOTTO, VILPOUX, 2016) e compartilham dos mesmos anseios e insegurança (SOUZA; SILVA; DUARTE, 2016) causados pela instabilidade do novo governo no que se refere aos cortes de recursos disponíveis para a educação superior, que atingem inevitavelmente a Assistência Estudantil.

Wilson (2010) aponta que o compartilhamento da informação se relaciona com os riscos assumidos, com a confiança depositada e proximidade organizacional. Notou-se que Confiança foi o item mais frequentemente apontado, $96 \%$ dos gestores afirmaram que o levam em consideração ao compartilhar informações, pois, confiam uns nos outros. A Proximidade Organizacional foi o segundo item mais destacado (18), seguido pelo Risco (17).

Como são todos concursados, não há concorrência entre os Gestores, ao contrário, eles se unem, no intuito de somarem forças para pleitear mais recursos perante o Governo Federal, estão todos engajados na luta por uma Universidade pública com qualidade e pela transformação do Decreto para Lei da Assistência Estudantil.

Quanto ao modo de como compartilham a informação, foi levantado que os canais apontados na Tabela 3 foram os mais frequentemente utilizados pelos gestores.

Tabela 3 - Canais utilizados para compartilhamento das informações

\begin{tabular}{l|c}
\hline \multicolumn{1}{c|}{$\begin{array}{c}\text { Canais utilizados para compartilhamento das } \\
\text { informações }\end{array}$} & $\%$ \\
\hline WhatsApp & $54 \%$ \\
\hline Site institucional & $50 \%$ \\
\hline E-mail & $50 \%$ \\
\hline Contato pessoal & $46 \%$ \\
\hline Redes sociais & $31 \%$ \\
\hline Telefone & $23 \%$ \\
\hline Ambiente virtual (fóruns, blogs) & $19 \%$ \\
\hline
\end{tabular}

Fonte: Dados da pesquisa (2020) 
O WhatsApp é o canal mais utilizado para o compartilhamento de informações pelos gestores, seguido por sites institucionais e e-mail.

Ao analisar o Compartilhamento Informacional, foi possível identificar a troca de informações e o fluxo de mão dupla apontado por Wilson (1999), entre os Gestores, pois eles fornecem e recebem informações que podem ajudar na sua atuação como gestor na instituição de ensino onde atuam.

\section{CONSIDERAÇÕES FINAIS}

As atividades desempenhadas pelos Gestores de Assistência Estudantil moldam o comportamento informacional, uma vez que as informações buscadas têm finalidade de satisfazer as necessidades para o exercício do seu cargo.

Os resultados encontrados nesta pesquisa permitem concluir que é possível melhorar o acesso dos Gestores de Assuntos Estudantis à informação que necessitam, disponibilizando o recurso e as fontes mais relevantes e confiáveis, bem como permitir a utilização de portais que reúnam todas as informações, referenciais bibliográficos e links que permitam encontrar essas informações, no caso, o Observatório Nacional de Acompanhamento Político de Assistência Estudantil, dede que, este esteja completo e atualizado.

Convém fazer uma reflexão sobre o uso do WhatsApp como uma das principais fontes de informações. Embora permita a resolução de questões operacionais de forma dinâmica e rápida, ele pode induzir os gestores ao erro, uma vez que, as informações ficam vulneráveis, podendo se perder. Além disso, a possibilidade de conseguir recuperar determinada informação é menor, visto que, muitas vezes, essas informações podem ser "ignoradas" num primeiro momento e até mesmo "apagadas". Portanto, o ambiente do WhatsApp não possibilita a criação de uma memória organizacional.

Por isso, é necessário que os gestores utilizem ferramentas mais perenes, que permitam o acesso, armazenamento, recuperação, compartilhamento e uso das informações.

Outro ponto a ser considerado diz respeito a importância de se pensar num sistema padronizado para todas as universidades no que se refere à gestão 
dos auxílios oferecidos com os recursos do PNAES, pois facilitaria a atualização cadastral dos estudantes e a análise dos dados, permitindo um melhor gerenciamento e utilização, assim como, a visualização do panorama geral do Brasil.

Destaca-se mais uma vez a importância do papel desempenhado por esses Gestores frente à realidade da atual conjuntura do país. Em meio a um desmonte da educação, tem-se a preocupação de ocorrer um retrocesso em tudo aquilo que já foi conquistado em anos de luta pelo FONAPRACE. Portanto, eles precisam estar munidos com o número maior de informações possíveis, mas, informações de qualidade, obtidas em fontes seguras, que lhes permitam tomar decisões assertivas.

Espera-se que os resultados da pesquisa possam servir como reflexão sobre a importância de políticas que privilegiem o processo informacional na gestão universitária. Almeja-se que a informação tenha o papel estratégico nas unidades de assistência estudantil, visando auxiliar o maior número possível de estudantes, diminuindo as taxas de evasão. Isso só poderá ser alcançado com informações de qualidade, como por exemplo, relevância, confiabilidade, precisão e veracidade.

Tendo em vista a importância da Assistência Estudantil para os estudantes com vulnerabilidade socioeconômica ingressantes nas Universidades Públicas, é interessante investigar o Comportamento Informacional dos técnico-administrativos que fazem o atendimento a esses estudantes, uma vez que eles tem o contato face a face e tem acesso à outras informações que permitem observar todo o contexto familiar.

Por acompanharem a trajetória acadêmica e a situação social dos estudantes mais de perto, os técnico-administrativos também precisam de informações técnicas das suas áreas, visando estarem sempre atualizados e oferecer o melhor atendimento. Eles tendem a ficar sensibilizados e solicitar os auxílios a um número maior de estudantes, daquilo que é possível oferecer com os recursos disponíveis, (mesmo que os estudantes atendam os critérios exigidos para o programa). Levanta-se então a questão de como estabelecer critérios dentro dos critérios. Por isso a importância de um trabalho conjunto com 
a gestão, para definirem políticas, diretrizes e métodos avaliativos para a Assistência Estudantil.

A investigação do comportamento informacional dos técnicoadministrativo permitirá verificar se há diferença do comportamento informacional dos Gestores ao comparar o "financeiro x humanização".

Também é interessante investigar o Comportamento Informacional dos estudantes atendidos pelos Programas de Assistência Estudantil, os "clientes", identificar quais são suas demandas e como buscam as informações. Vale ressaltar que boa parte dos estudantes que ingressam na universidade, não tem o conhecimento imediato da existência dos auxílios. Portanto, as Pró-Reitorias de Assuntos Estudantis poderiam viabilizar uma plataforma única, que centralizasse todas as informações.

Outras pesquisas poderiam ser realizadas em Pró-Reitorias de Graduação, de Pesquisa e Pós-graduação, de Planejamento, de Administração, no intuito de perceber se o contexto realmente molda o Comportamento Informacional.

\section{REFERÊNCIAS}

ARAÚJO, C. A. A. Um mapa dos estudos de usuários da informação no Brasil. Em Questão, [s.I.], v. 5, n. 1, p. 11-26, 2009.

ARAÚJO, C. A. A. Estudo de usuários conforme o paradigma social da ciência da informação: desafios teóricos e práticos de pesquisa. Informação \& Informação, Londrina, v. 15, n. 2, p. 23-39, 2010.

ARAÚJO, C. A. A. Estudos de usuários da informação: comparação entre estudos de uso, de comportamento e de práticas a partir de uma pesquisa empírica. Inf. Pauta, Fortaleza, CE, v. 1, n. 1, jan/jun, 2016.

ARAÚJO, N. C.; FACHIN, J. Evolução das fontes de informação. Biblos:

Revista do Instituto de Ciências Humanas e da Informação, [ s.l.], v. 29, n. $1,2015$.

BAGGIO, C. C.; COSTA, H.; BLATTMANN, U. Seleção de tipos de fonte de informação. Perspectivas em Gestão \& Conhecimento, [s.I.], v. 6, n. 2, p. 3247, jul/dez, 2016. 
BARDIN, L. Análise de conteúdo. Lisboa: Edições 70, 2016.

BATES M. J. Information Behavior. In: BATES M. J.; MAACK, M. N (Org). Encyclopedia of Library and Information Sciences, 3 ed., New York, NY: CRC Press, v. 3, p. 2347-2360, 2010.

CASE, D. O. Looking for Information: a survey of research on information seeking, needs, and behavior. 4. ed. Edição do Kindle. United Kingdon: Esmerald, 2016.

$\mathrm{CHOO}, \mathrm{C}$. W. A organização do conhecimento: como as organizações usam a informação para criar significado, construir conhecimento e tomar decisões. 2. ed. São Paulo: SENAC Editora, 2006.

$\mathrm{CHOO}, \mathrm{C}$. W. A organização do conhecimento: como as organizações usam a informação para criar significado, construir conhecimento e tomar decisões. São Paulo: SENAC, 2003.

DAS, K. C.; ACHARY, J. Information needs, information seeking Behaviour and use of Electronic resources by Research scholars and Faculties in the University and Research libraries of Odisha. Journal of Library \& Information Science, [s.I.], v. 4, n. 4, Dec, 2014.

DAVENPOURT, T. H.; PRUSAK, L. Ecologia da Informação: porque só a tecnologia não basta para o sucesso na área da informação. São Paulo: Futura, 1998.

DERVIN, B.; FOREMAN-WERNET, L.; LAUTERBACH, L. Sense-Making Methodology reader: Select writings of Branda Dervin. Cresskill: Hampton Press, 2003.

DU, J. T. The information Journey of Marketings Professionals: Incorporating Work Task-Driven Information Seeking, Information Judgments, Information Use and Information Sharing. Journal of the Association for Information Science \& Technology, [s.I.], v. 65, n. 9 p. 1850-1869, Sep, 2014.

ELLIS, D. A behavioral model for information retrieval system design. Journal of Documentation, v. 45, n.3, p. 171-212, 1989.

FONAPRACE. V Pesquisa do Perfil Socioeconomico dos graduandos (as) das IFES - 2018. Disponível em http://www.andifes.org.br/wpcontent/uploads/2019/05/V-Pesquisa-do-Perfil-Socioecon\%C3\%B4mico-dosEstudantes-de-Gradua\%C3\%A7\%C3\%A3o-das-Universidades-Federais1.pdf>. Acesso em 10 de set. 2019.

GASGUE, K. C. G. D; COSTA, S. M. S. Evolução teórico-metodológica dos estudos de comportamento informacional de usuários. Ci. Inf., Brasília, DF, v. 30 n. 1, p. 21-32, jan/abr, 2010. 
GIL, A. C. Métodos e técnicas de pesquisa social. 6. ed. São Paulo: Atlas, 2008.

KUHLTHAU, C. C. A Principle of Uncertainty for Information Seeking. Journal of Documentation, [s.l.], v. 49, n. 4, p. 339-355, 1993.

KWASITSU, L.; CHIU, A. M. Mobile information behavior of Warner Pacific University students. Library and Information Science Research, [s.I.], v. 41, p. $139-150,2019$

MACHADO. G. C.; BARBOSA, R. R. O comportamento informacional de líderes religiosos em Belo Horizonte. Informação em Pauta, Fortaleza, v. 3, n. 2, p. 10-30, jul/dez 2018.

MALAQUIAS, F. F. O.; VIEIRA, A. L.; ESPÍNDOLA, D. M.; GOMES, G. C.; ROSA M. H.; SILVA R. D. Comportamento Informacional: um estudo com alunos do curso de administração. Estudo \& Debate, Lajeado, v. 24, n. 2, p. 175-191, 2017.

MARTÍNEZ-SILVEIRA, M.; ODDONE, N. Necessidade e comportamento informacional: conceituação e modelos. Ci. Inf., Brasília, v. 36, n. 1, p. 118-127, maio/ago, 2007.

MICHEL, M. H. Metodologia e pesquisa científica em ciências sociais: um guia prático para acompanhamento da disciplina e elaboração de trabalhos monográficos. 3. Ed. São Paulo: Atlas, 2015.

NASCIMENTO, N. M.; VITORIANO, M. C. C. P. Comportamento informacional nas organizações: a busca e o uso de informações no processo de avaliação documental. ẢGORA, Florianópolis, v. 27, n. 54, p. 126-157, jan/jun 2017.

PEREIRA, F. C. M. Necessidades e uso da informação: a influência dos fatores cognitivos, emocionais e situacionais no comportamento informacional de gerentes. Perspectiva em Ciência da Informação, [s.I.], v. 15, n. 3, p. 176194, set/dez, 2010.

PEREIRA, F. C. M. Modelo Integrativo sobre Comportamento Informacional em processos decisórios. R. Adm. FACES Journal, Belo Horizonte, v. 15, n. 3 p. 27-49, jul/set, 2016.

RODRIGUES, C.; BLATTMANN, U. Gestão da informação e a importância do uso de fontes de informação para geração de conhecimento. Perspectiva em Ciência da Informação, [s.I.], v. 19, n. 3, p. 4-29, 2014.

RODRIGUES, V. L; CARDOSO, A. M. P. O campo de estudo de usuários na ciência da informação brasileira: uma revisão sistemática da literatura. Em Questão, Porto Alegre, v. 23, n. 2, p. 234-251, maio/ago, 2017. 
SECO, L. F. C.; SANTOS, Z. P. S.; BARTALO, L. Comportamento informacional e compartilhamento da informação no Instagram. Revista ACB: Biblioteconomia em Santa Catarina, v. 21, n. 1, p. 46-60, dez/mar, 2016.

SILVA, H. C. H.; BINOTTO, E.; VILPOUX, O. F. Cooperação e compartilhamento de informação entre os atores sociais em um assentamento rural. Perspectiva em Gestão e Conhecimento, João Pessoa, v. 6, n. 1, p. 89-108, jan/jun 2016.

SOUZA, L. B. R. H.; SILVA, A. K. A.; DUARTE, E. N. A produção do conhecimento sobre compartilhamento da informação e do conhecimento. Informação \& Sociedade, João Pessoa, v. 26, n. 3, p. 209-220, set/dez, 2016.

TARAPANOFF, K. (org). Aprendizagem Organizacional: fundamentos e abordagens multidisciplinares. Curitiba: IBEPEX, 2011. v. 1.

UCHE, E.; NDIDI, N. G. Information needs and seeking behaviour of engineering lecturers in Nigerian Universities: The case of Chukwuemeka Odumegwu Ojukwu University, Anambra State. Library Philosophy and Practice, [s.I.], p.1, jul, 2018.

VITORIANO, M. A. V.; GASQUE, K. C. G. Comportamento de pesquisa e uso de informações irrelevantes de trabalho. Encontros Bibli: Revista Electronica de Biblioteconomia e Ciência da Informação, v. 23, n. 53, p. 78-86, set/dez, 2018.

WILSON, T. D. On user studies and information needs. Journal of Documentation, London, v. 37, n. 1, p. 3-15, 1981.

WILSON, T. D. Models in information behavior research. Journal of Documentation, London, v. 55, n. 3, p. 249-270, jun, 1999.

WILSON, T. D. Human information behavior. Informing Science Research, [s.l.], v. 3, n. 2, 2000.

WILSON, T. D. Information Sharing: an exploration of the literature and some propositions. Information Research, [s.I.], n. 4, v. 15, Dec. 2010.

WILSON, T. D. WALSH, C. Information behavior: an inter-disciplinary perspective. British Library Research and Innovation Report, [s.I.], n. 10, 1996.

\section{INFORMATIONAL BEHAVIOR OF STUDENT AFFAIRS MANAGERS FROM FEDERAL UNIVERSITIES IN BRAZIL}

\section{ABSTRACT}


Introduction: Informational Behavior refers to the many ways in which people interact with information, particularly, as ways in which the individual perceives, seeks, understands and uses information in the various contexts of life. Objective: The article presents the results of a master's research that analyzed the informational behavior of student affairs managers at federal universities in Brazil. Methodology: This is a descriptive study with a qualitative and quantitative approach. Data collection took place with the application of a questionnaire, semi-structured interview and documentary analysis of the documents generated by the National Forum of Pro-Rectors of Student Affairs. The research was guided by the Informational Behavior model developed by Wilson (1981/1996). Results: Information needs were identified to answer questions, make decisions and generate knowledge. As for the search for information, personal contact was identified as the main source of information, the presence of sometime and technology barriers was noted (lack of a standardized and integrated system). The information is used to develop policies and actions for student assistance, accountability and, mainly, for decision making. Information is shared by the Ciranda email group and WhatsApp, taking into account organizational proximity, trust and perceived risks. Conclusions: It is possible to improve the access of managers to the information they need, making available the resource and relevant and reliable sources, making them aware of the use of more perennial tools that allow access, storage, retrieval and use of information, allowing them make assertive decisions.

Descriptors: Information. Informational Behavior. Student Assistance. FONAPRACE.

\title{
COMPORTAMIENTO INFORMACIONAL DE GERENTES DE ASISTENCIA ESTUDIANTIL EN UNIVERSIDADES PÚBLICAS FEDERALES EN BRASIL
}

\begin{abstract}
RESUMEN
Introducción: El comportamiento informacional se refiere a las muchas formas en que las personas interactúan con la información, en particular, las formas en que el individuo percibe, busca, comprende y utiliza la información en los diversos contextos de la vida. Objetivo: El artículo presenta los resultados de una investigación de maestría que analizó el comportamiento informativo de los gerentes de asuntos estudiantiles en las universidades federales de Brasil. Metodología: Este es un estudio descriptivo con un enfoque cualitativo y cuantitativo. La recolección de datos se realizó con la aplicación de un cuestionario, una entrevista semiestructurada y un análisis documental de los documentos generados por el Foro Nacional de Pro-Rectores de Asuntos Estudiantiles. La investigación se guio por el modelo de comportamiento informativo desarrollado por Wilson (1981/1996). Resultados: Se identificaron necesidades de información para responder preguntas, tomar decisiones y generar conocimiento. En cuanto a la búsqueda de información, se identificó el contacto personal como la principal fuente de información, se observó la presencia de algún tiempo y barreras tecnológicas (falta de un sistema estandarizado e integrado). La información se utiliza para desarrollar políticas y acciones de asistencia estudiantil, responsabilidad y, principalmente, para la toma de decisiones. La información es compartida por el grupo de correo electrónico de Ciranda y WhatsApp, teniendo en cuenta la proximidad de la organización, la confianza y los riesgos percibidos. Conclusiones: es posible mejorar el acceso de los gerentes a la información que necesitan, poniendo a disposición los recursos y fuentes relevantes y confiables, haciéndolos conscientes del uso de herramientas más perenes que
\end{abstract}


permiten el acceso, almacenamiento, recuperación y uso de la información, permitiéndoles tomar decisiones asertivas.

Descriptores: Información. Comportamiento Informacional. Asistencia Estudiantil. Fonaprace.

Recebido em: 18.05.2020

Aceito em: 12.08 .2020 